\title{
The ENFUMOSA cross-sectional European multicentre study of the clinical phenotype of chronic severe asthma
}

\author{
The ENFUMOSA Study Group*
}

\begin{abstract}
The ENFUMOSA cross-sectional European multicentre study of the clinical phenotype of chronic severe asthma. The ENFUMOSA Study Group. C) ERS Journals Ltd 2003.

ABSTRACT: Since severe asthma is a poorly understood, major health problem, 12 clinical specialist centres in nine European countries formed a European Network For Understanding Mechanisms Of Severe Asthma (ENFUMOSA).

In a cross-sectional observational study, a total of 163 subjects with severe asthma were compared with 158 subjects whose asthma was controlled by low doses of inhaled corticosteroids (median dose of beclomethasone equivalents $666 \mu \mathrm{g}$ ). Despite being treated with higher doses of inhaled corticosteroids (median dose $1773 \mu \mathrm{g}$ ) and for a third of the severe asthmatics also being treated with regular, oral-steroid therapy (median daily dose $19 \mathrm{mg}$ ), the subjects with severe asthma met the inclusion criteria. The criteria required subjects to have undergone at least one asthma exacerbation in the past year requiring oral steroid treatment. Females dominated the severe asthma group (female/male ratio 4.4:1 versus 1.6:1 in the controlled asthmatics), and compared with controlled asthmatics, they had a predominantly neutrophilic inflammation (sputum neutrophils, 36 versus $28 \%$ ) and evidence of ongoing mediator release but less atopy.

From these findings and other physiological and clinical data reported in this paper, it is suggested that severe asthma might be a different form of asthma rather than an increase in asthma symptoms. The findings prompt for longitudinal studies and interventions to define the mechanisms in severe asthma.

Eur Respir J 2003; 22: 470-477.
\end{abstract}

Correspondence: S.T. Holgate, Respiratory Cell and Molecular Biology Research Division, Mail Point 810, Level D, Centre Block, Southampton General Hospital, Southampton SO16 6YD, UK.

Fax: 442380796960

E-mail:sth@soton.ac.uk

Keywords: Asthma, atopy, clinical characteristics, disease severity, inflammatory biomarkers, sex-related disease

Received: July 192001

Accepted after revision: May 292003

This work was supported by a Concerted Action Grant for the European Union Framework IV Biomed Programme No. BMH4-961471, National Research Foundations in the participating countries, and unconditional support from several corporations including AstraZeneca, Bayer AG, Jaeger $\mathrm{GmbH}$, Novartis Epidemiology, Pharmacia \& Upjohn Diagnostics and SmithKline Beecham.
Asthma is an inflammatory disorder of the airways associated with airflow obstruction and bronchial hyperresponsiveness that varies in severity across the spectrum of the disease. Although therapy, used according to management guidelines, controls the disease in the majority of patients, it is recognised that a subgroup of asthmatics show reduced responsiveness to the standard therapy and experience greater morbidity and a lower quality of life than those asthmatics whose disease is adequately controlled by therapy [1]. These more severe asthmatics, which account for $\sim 10 \%$ of the asthmatic population, have a disproportionate impact on healthcare utilisation, accounting for up to at least half of the direct and indirect costs for asthma [2]. Asthmatics whose disease is inadequately controlled have more extensive use of asthma medication. It has been identified that these individuals are 15 times as likely to use emergency medical care as mild-to-moderate asthmatics and are 20 times as likely to require hospital admission [2]. These severe asthmatics also have greater absenteeism from work on account of their disease.

There is little information on the pathophysiological mechanisms responsible for severe and persistent asthma. Some small studies of severe asthma, using induced sputum to assess the airway inflammatory response, have shown that despite the regular use of high-dose inhaled and oral corticosteroids, eosinophilia persists. However, the numbers of cells and their state of activation, seem to show little difference between patients with severe asthma compared to patients with the mild-to-moderate form of the disease [3-5]. Patients with more severe disease are increasingly likely to have impaired lung function as studies have shown that despite the use of high doses of inhaled and oral corticosteroids, severe asthma is associated with a component of airflow obstruction that appears either nonreversible or at best difficult to reverse $[1,6]$.

Atopy has long been recognised as the risk factor that has the greatest influence on the emergence of persistent asthma in childhood, especially sensitisation to aeroallergens in the home [7]. In contrast, atopy may be less important in patients with adult asthma and other factors such as intolerance to aspirin and related nonsteroidal anti-inflammatory drugs (NSAIDs) as well as occupational exposures have been suggested to play an important role in adults with more severe asthma [1,8].

In view of the impact of severe asthma on healthcare resources and the need to understand the mechanisms

For editorial comments see page 397.

*ENFUMOSA: The European Network For Understanding Mechanisms Of Severe Asthma (investigators: B. Abraham, J.M. Antó, E. Barreiro, E.H.D. Bel, G. Bonsignore, J. Bousquet, J. Castellsague, P. Chanez, F. Cibella, G. Cuttitta, B. Dahlén, S-E. Dahlén, N. Drews, R. Djukanovic, L.M. Fabbri, G. Folkerts, M. Gaga, C. Gratziou, G. Guerrera, S.T. Holgate, P.H. Howarth, S.L. Johnston, F. Kanniess, J.C. Kips, H.A.M. Kerstjens, M. Kumlin, H. Magnussen, F.P. Nijkamp, N. Papageorgiou, A. Papi, D.S. Postma, R.A. Pauwels, K.F. Rabe, K. Richter, A.C. Roldaan, M. Romagnoli, A. Roquet, C. Sanjuas, N.M. Siafakas, W. Timens, N. Tzanakis, I. Vachier, A.M. Vignola, L. Watson and G. Yourgioti). 
Table 1. - Participating centres

\begin{tabular}{|c|c|c|c|}
\hline City/country & University & Hospital/affiliations & Investigators \\
\hline Athens, Greece & University of Athens & $\begin{array}{l}\text { Sotiria Chest Hospital } \\
\text { Evgenidio Hospital } \\
\text { AstraZeneca }\end{array}$ & $\begin{array}{l}\text { M. Gaga, N. Papageorgiou } \\
\text { C. Gratziou } \\
\text { G. Yourgioti }\end{array}$ \\
\hline Barcelona, Spain & $\begin{array}{l}\text { Institut Municipal d'Investigació } \\
\text { Mèdica }\end{array}$ & $\begin{array}{l}\text { Hospital del Mar } \\
\text { Novartis Global Epidemiology }\end{array}$ & $\begin{array}{l}\text { J.M. Antó, E. Barreiro, C. Sanjuas } \\
\text { J. Castellsague }\end{array}$ \\
\hline Ferrara, Italy & Universita degli Studi di Ferrara & $\begin{array}{l}\text { Clinica di Malattie } \\
\text { dell'Apparato Respiratorio }\end{array}$ & L.M. Fabbri" ${ }^{\#}$ A. Papi, M. Romagnoli \\
\hline Ghent, Belgium & University of Ghent & Ghent University Hospital & J.C. Kips, R.A. Pauwels \\
\hline $\begin{array}{l}\text { Groningen, The } \\
\text { Netherlands }\end{array}$ & University of Groningen & University Hospital, Groningen & H.A.M. Kerstjens, D.S. Postma, W. Timens \\
\hline Hamburg, Germany & University of Hamburg & Krankenhaus Großhansdorf & $\begin{array}{l}\text { N. Drews, F. Kanniess, H. Magnussen, } \\
\text { K. Richter }\end{array}$ \\
\hline Heraklion, Greece & University of Heraklion & Heraklion University Hospital & N.M. Siafakas, N. Tzanakis \\
\hline $\begin{array}{l}\text { Leiden, The } \\
\text { Netherlands }\end{array}$ & Leiden University & $\begin{array}{l}\text { Leiden University Medical } \\
\text { Centre Leyenburg Hospital }\end{array}$ & E.H.D. Bel, K.F. Rabe A.C. Roldaan \\
\hline Montpellier, France & University of Montpellier & Hopital Arnaud de Villeneuve & J. Bousquet, P. Chanez, I. Vachier \\
\hline Palermo, Italy & Universita degli Studi di Palermo & Ospedale V Cervello & $\begin{array}{l}\text { G. Bonsignore, F. Cibella, G. Cuttitta, } \\
\text { G. Guerrera, A.M. Vignola }\end{array}$ \\
\hline Southampton, UK & University of Southampton & Southampton General Hospital & $\begin{array}{l}\text { B. Abraham, R. Djukanovic, S.T. Holgate, } \\
\text { P.H. Howarth, S.L. Johnston }{ }^{-} \text {, L. Watson }\end{array}$ \\
\hline Stockholm, Sweden & Karolinska Institutet & Karolinska Hospital & $\begin{array}{l}\text { B. Dahlén }{ }^{+}, \text {S-E. Dahlén, M. Kumlin, } \\
\text { A. Roquet }\end{array}$ \\
\hline $\begin{array}{l}\text { Utrecht, The } \\
\text { Netherlands }\end{array}$ & University of Utrecht & (analytical centre) & G. Folkerts, F.P. Nijkamp \\
\hline
\end{tabular}

Current affiliations: ${ }^{\#}$ : University of Modena, Italy; ${ }^{\circ}$ Imperial College, London, UK; ${ }^{+}$: Huddinge University Hospital, Stockholm, Sweden.

involved in severe asthma, a European Network For Understanding Mechanisms Of Severe Asthma (ENFUMOSA) was established (table 1). The ENFUMOSA group developed a common methodology and applied this to recruit a cohort of patients with severe disease from 12 centres in nine European countries. This paper reports on the findings in the first cross-sectional attempt to compare clinical, physiological and laboratory measures in subjects with severe asthma and a similar sized cohort of asthmatics, whose disease was controlled with low to moderate doses of inhaled corticosteroids (ICS). The purpose of this first study was primarily to subject a sufficiently large cohort of patients to the same investigations in order to obtain reliable data on the phenotype of severe asthma. It was anticipated that this endeavour would generate hypotheses for future studies by the ENFUMOSA group.

\section{Materials and methods}

\section{Study design}

The study was a cross-sectional, multicentre comparison between patients with severe asthma and a group of patients with mild-to-moderate asthma, controlled by low to medium doses of ICS. In addition to a common study-protocol, a detailed procedure handbook was developed to define the methodology. Meetings and methodology workshops were also held for staff during the initiation of the study in order to achieve a uniform study-conduct at all participating centres. The clinical and laboratory measurements were generally collected on two or three visits on separate days during the same week.

\section{Subjects}

Patients aged between 17-65 yrs whose asthma had been diagnosed by a specialist before the age of 45 yrs and who had been receiving daily therapy with ICS for a minimum of $1 \mathrm{yr}$ were recruited from specialist outpatient clinics at the participating centres. All patients had to have previous evidence of variable airways obstruction within the last $5 \mathrm{yrs}$, as documented by at least one of the following. 1) Reversibility in forced expiratory volume in one second (FEV1) of $\geqslant 9 \%$ predicted after 4 puffs of a $100 \mu \mathrm{g}$ salbutamol dose-aerosol, administered via a spacer. 2) A mean diurnal variation in peak expiratory flow (PEF) $\geqslant 15 \%$ (highest PEF-lowest PEF) per mean PEF on $\geqslant 4$ days per week for a minimum of 2 weeks. 3) An increase in FEV1 of $\geqslant 400 \mathrm{~mL}$ after a course of prednisolone $0.5 \mathrm{mg} \cdot \mathrm{kg}^{-1} \cdot \mathrm{day}^{-1}$ for 14 days. 4) A provocative concentration causing a $20 \%$ fall in FEV1 with histamine or methacholine $<8 \mathrm{mg} \cdot \mathrm{mL}^{-1}$. Patients were excluded if they were cigarette smokers, with a smoking history of $\geqslant 5$ pack years, and if they had started smoking before their diagnosis of asthma, irrespective of the level of their cigarette use. Patients were also excluded if they had other active acute or chronic pulmonary disorders, or had clinically significant psychiatric disease. Patients were not allowed to be receiving immunosuppressant therapy other than corticosteroids.

The patients were divided into those with severe disease and those with mild-to-moderate disease on the basis of: 1) the level of their regular treatment with ICS; and 2) their history of asthma exacerbations in the last year. Patients with controlled asthma were treated with a maximum of $1,000 \mu \mathrm{g} \cdot \mathrm{day}^{-1}$ budesonide or beclomethasone (or $500 \mu \mathrm{g} \cdot \mathrm{day}^{-1}$ fluticasone or equivalent) and had no asthma exacerbations in the past year. Inclusion in the severe asthma group required one asthma exacerbation in the last year despite treatment with $\geqslant 1,200 \mu \mathrm{g} \cdot \mathrm{day}^{-1}$ budesonide or beclomethasone, or equivalent doses of other ICS, or oral corticosteroids. An asthma exacerbation was defined either by the initiation of a course of oral corticosteroid (OCS) therapy in those on regular ICS treatment, or for those on regular OCS therapy, a significant temporary increase in their dose of oral steroids for an acute deterioration in their disease control. For certain results, the 
findings taken from patients kept only on ICS were compared with those patients on OCS.

\section{Questionnaires}

At enrolment each subject was asked to complete a clinical questionnaire adapted from the expert system for asthma severity, previously developed in Montpellier [9]. This standardised the collection of data on the presence and severity of the asthma symptoms and the medical history.

\section{Clinical measures}

In addition to complete physical examination, patients had their height and weight recorded and measurements were made of the respiratory rate, cardiac frequency and blood pressure (systolic and diastolic) at rest. All patients underwent epicutaneous skin-prick testing on the flexor surface of their forearm to a range of allergens and to a positive (histamine acid phosphate $\left.1 \mathrm{mg} \cdot \mathrm{mL}^{-1}\right)$ and a negative control $(0.9 \%$ saline) according to a standardised protocol. The allergens tested were mixed grass pollen, cat fur, dog hair, dermatophagoides pterronissinus, Alternaria, Aspergillus fumigatus and two additional common local aeroallergens chosen according to the prevalence of allergens in each country (Soluprick ${ }^{\mathrm{TM}}$, ALK Lab, Copenhagen, Denmark). The maximum wheal diameter and its perpendicular diameter were measured at 15 min intervals. A positive response was taken as a wheal $\geqslant 3 \mathrm{~mm}$ in comparison with the negative control. Subjects with a negative histamine control were excluded.

\section{Laboratory measures}

Pulmonary function. FEV1 and forced vital capacity (FVC) were measured at each centre with calibrated spirometers according to published guidelines [10]. The highest value of three consecutive recordings was used. The maximum achievable lung function after inhalation of a bronchodilator was measured as the percentage increase in FEV1, 15 min after inhalation of salbutamol $400 \mu \mathrm{g}$, although it was not considered ethical to ask patients with severe asthma to withhold their bronchodilator for $6 \mathrm{~h}$ before reversibility was assessed. Lung volumes were assessed after the bronchodilator test as total lung capacity (TLC), residual volume (RV) and vital capacity (VC), using the single breath helium gas dilution method. Carbon monoxide transfer factor was measured using the single breath method [11] and the result divided by the alveolar volume, to provide the carbon monoxide transfer coefficient $(\mathrm{KCO})$. Predicted values for the different measures were calculated from the published regression equations [10].

Peripheral blood measures. Venous blood was taken into ethylenediamine tetraacetic acid for measurement of the total and differential white blood count (WBC) by standard Coulter counting and a separate sample taken for total serum immunoglobulin (Ig)E measurement by fluorimmunoassay $\left(\mathrm{CAP}^{\mathrm{TM}}\right.$, Pharmacia Upjohn, Uppsala, Sweden). This method has a detection limit of $2 \mathrm{kU} \cdot \mathrm{L}^{-1}$ and an interassay coefficient of variation of $3-7 \%$ over a range of $6-800 \mathrm{kU} \cdot \mathrm{L}^{-1}$. An arterial blood sample was also taken for measurement of resting arterial blood gases, as measured by standard clinical methods.

Inflammatory markers. Induced sputum was obtained from those centres in which this technique was established using a common standard protocol in which stepwise increasing concentrations of hypertonic saline $(0.9,3,4$ and $5 \%)$ were administered $15 \mathrm{~min}$ after the inhalation of salbutamol $(200 \mu \mathrm{g})$ [12]. Only patients whose postbronchodilator FEV1 was $>50 \%$ predicted were eligible for sputum induction. After each concentration step subjects were encouraged to expectorate sputum. The procedure was stopped when a sample had been produced, or if FEV1 fell by $>20 \%$ of baseline, or if the highest concentration of hypertonic saline had been reached. The more viscid portions were selected from the sample, weighed and incubated with an equal volume of $0.1 \%$ dithiothreitol for $15 \mathrm{~min}$ on a bench rocker at room temperature. The sample was centrifuged, the supernatant stored for mediator assays and the pellet resuspended in phosphate-buffered saline $(\mathrm{pH} 7.4)$ supplemented with $1 \%$ human serum albumin. Cytospins were prepared, air dried, fixed and then stained with May-Grünwald and Giemsa, or toluidine blue. Cells were counted as a proportion of 400 cells and metachromatic cells as a proportion of 1,500 cells.

Exhaled nitric oxide (NO) was measured by chemiluminescence analysis using standardised equipment-methods at the centres with the necessary facilities.

At clinic visits all urine voided between 09:00 and 12:00 h was collected and frozen at $-20^{\circ} \mathrm{C}$ for centralised measurements of leukotriene (LT) $\mathrm{E}_{4}$ and eosinophil protein X (EPX) using previously validated immunoassays [13]. Urinary measures were expressed in relation to the creatinine concentrations.

Data analysis. All clinical, questionnaire and laboratory data were entered on a specially constructed clinical report form. The data were submitted to a single statistical centre (J. Castellsague, Barcelona) where it was checked for accuracy and then entered into a database. Comparisons of measures were made between the mild-to-moderate and severe asthmatics after first displaying the distribution and checking for normality, then subjecting the groups to analyses of variance or unpaired t-tests, as appropriate. In the case of total serum $\mathrm{IgE}$ and $\mathrm{NO}$, the values were logarithmically transformed to achieve normality and then converted back to geometric means. Geometric means were adjusted by age and sex. Variables not fitting a normal distribution after transformation were compared with the Mann-Whitney's signed rank test, while categorical values were compared with the Chi-squared test. Odds ratios (OR) were estimated with their respective $95 \%$ confidence intervals (CI). Crude OR are reported given that adjustment for age and sex did not change the magnitude of any of the associations $(<10 \%)$.

\section{Results}

\section{Patient demographics}

A total of 321 patients were recruited comprising of 163 with severe and 158 with mild-to-moderate asthma. The characteristics of the patients are shown in table 2. There were no differences between the two groups in their age. However, females dominated the severe asthma group (female:male, 4.4:1 in the severe group versus 1.6:1 in the controlled group, $\mathrm{p}<0.001)$. Expressed differently, females were 2.8 times more common in the severe asthma group than males. This was a consistent finding in all participating regions of Europe (table 3). Within each sex, there were no major differences in height between those with severe and those with controlled asthma. The females with severe disease weighed more and had a greater body mass index than the females with nonsevere asthma (table 2). The group with severe asthma had a higher systolic and diastolic blood pressure although differences were only statistically significant in females (table 2). Those with severe asthma also had a 
Table 2.-Study subjects' demographic and clinical characteristics

\begin{tabular}{|c|c|c|c|}
\hline & Controlled asthma & Severe asthma & Controlled versus severe asthma \\
\hline Subjects $n$ & 158 & 163 & \\
\hline Age yr & $40.9 \pm 14.3$ & $42.4 \pm 12.1$ & NS \\
\hline Sex ratio female:male & 1.6:1 & $4.4: 1$ & $\mathrm{p}<0.001$ \\
\hline \multicolumn{4}{|l|}{ Height $\mathrm{cm}$} \\
\hline Male & $175.3 \pm 8.4$ & $172.2 \pm 7.6$ & NS \\
\hline Female & $161.7 \pm 8.1$ & $161.7 \pm 7.4$ & NS \\
\hline \multicolumn{4}{|l|}{ Weight kg } \\
\hline Male & $78.6 \pm 14.9$ & $80.4 \pm 16.3$ & NS \\
\hline Female & $66.5 \pm 11.4$ & $70.9 \pm 15.5$ & $\mathrm{p}<0.05$ \\
\hline \multicolumn{4}{|l|}{$\mathrm{BMI} \mathrm{kg} \cdot \mathrm{m}^{-2}$} \\
\hline Male & $26.3 \pm 6.4$ & $26.5 \pm 4.2$ & NS \\
\hline Female & $25.6 \pm 4.9$ & $27.2 \pm 6.0$ & $\mathrm{p}<0.05$ \\
\hline \multicolumn{4}{|l|}{ Systolic BP mmHg } \\
\hline Male & $127.0 \pm 24.6$ & $131.4 \pm 11.9$ & $\mathrm{p}<0.01$ \\
\hline Female & $123.1 \pm 20.1$ & $130.2 \pm 19.7$ & $\mathrm{p}<0.01$ \\
\hline \multicolumn{4}{|l|}{ Diastolic BP mmHg } \\
\hline Male & $79.6 \pm 10.7$ & $83.1 \pm 7.0$ & $\mathrm{p}<0.001$ \\
\hline Female & $76.8 \pm 10.8$ & $82.0 \pm 12.1$ & $\mathrm{p}<0.001$ \\
\hline \multicolumn{4}{|l|}{ Heart frequency beats $\cdot \min ^{-1}$} \\
\hline Male & $67.7 \pm 10.8$ & $82.3 \pm 19.3$ & $\mathrm{p}<0.001$ \\
\hline Female & $73.9 \pm 9.2$ & $82.7 \pm 14.6$ & $\mathrm{p}<0.001$ \\
\hline \multicolumn{4}{|l|}{ Respiratory rate per min } \\
\hline Male & $15.4 \pm 3.6$ & $16.7 \pm 3.5$ & NS \\
\hline Female & $16.9 \pm 4.2$ & $18.1 \pm 4.5$ & $\begin{array}{c}\mathrm{NS} \\
\mathrm{p}<0.01^{\text {ब }}\end{array}$ \\
\hline Dose of inhaled steroid ${ }^{\#}$ & $666 \pm 285$ & $1676 \pm 667$ & $\mathrm{p}<0.001$ \\
\hline
\end{tabular}

All data are expressed as mean \pm SD unless otherwise indicated. BMI: body mass index; BP; blood pressure; ${ }^{\#}$ : steroid expressed as beclomethasone equivalents; ${ }^{\circ}$ : for males and females combined.

higher cardiac frequency and a significantly greater respiratory rate (table 2). In line with asthma exacerbations being an inclusion criterion, over one third $(39.5 \%)$ of those with severe asthma had also required at least one hospital admission for treatment of their asthma in the preceding year.

\section{Atopy}

Analyses of different markers of atopy consistently showed that this was inversely related to asthma severity. Age and sex adjusted geometric mean total serum IgE was lower in the severe asthmatics $(109,95 \%$ CI 85-139) than in those with

Table 3. - Sex ratio distribution among subjects with severe asthma from the different participating centres

\begin{tabular}{lccc}
\hline Centre & Severe asthma n & Female n (\%) & $\begin{array}{c}\text { Ratio } \\
\text { female:male }\end{array}$ \\
\hline Montpellier & 15 & $9(60)$ & 1.50 \\
Groningen & 8 & $6(75)$ & 3.00 \\
Leiden & 12 & $9(75)$ & 2.25 \\
Palermo & 17 & $13(76)$ & 3.25 \\
Ghent & 9 & $7(78)$ & 3.50 \\
Ferrara & 14 & $11(79)$ & 3.67 \\
Grosshansdorf & 10 & $8(80)$ & 4.00 \\
Barcelona & 8 & $7(88)$ & 7.00 \\
Southampton & 18 & $16(89)$ & 8.00 \\
Stockholm & 20 & $18(90)$ & 9.00 \\
Athens & 21 & $19(90)$ & 9.50 \\
Heraklion & 11 & $10(91)$ & 10.00 \\
Total & 163 & $133(82)$ & \\
\hline
\end{tabular}

Mean odds ratio female versus male (95\% CI): 2.69 (1.6-4.49); Chi-squared p-value 0.001 . controlled disease $(148,95 \%$ CI $118-188$ units; $\mathrm{p}<0.05)$. Skinprick tests with eight common aeroallergens also revealed fewer positive reactions in the severe asthma group (fig. 1). This difference was identified in all participating regions. The only skin-prick tests that showed no significant differences between the severe and controlled asthmatics were Alternaria and Aspergillus fumigatus, but these were positive in only $8-11 \%$ of patients in either of the asthma groups. In a multiple linear regression model controlling for the number of

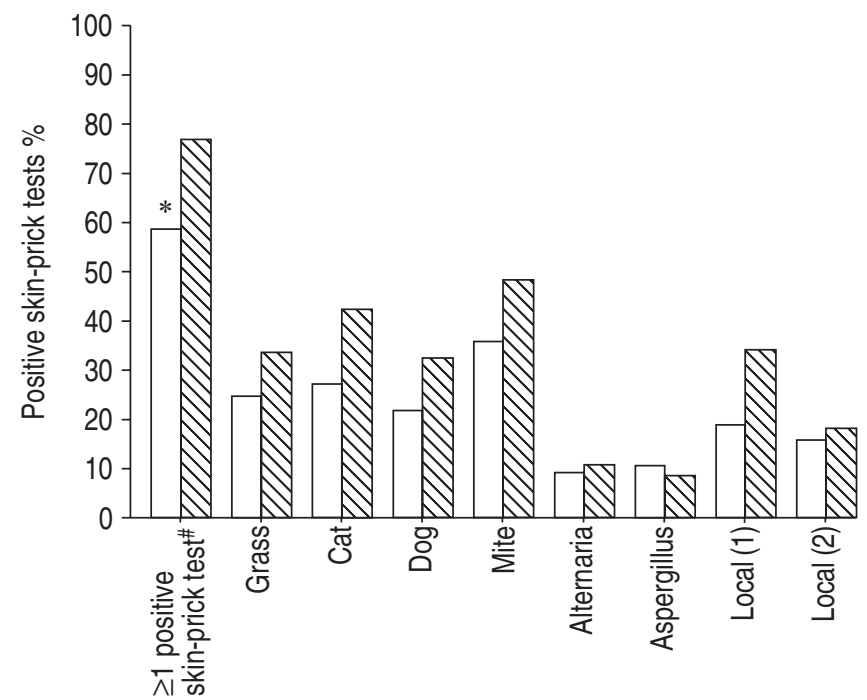

Fig. 1. - Percentage of positive skin-prick tests to common aeroallergens in asthmatic patients with well-controlled $(\mathbb{\mathbb { Q }})$ or severe $(\square)$ asthma. ${ }^{\#}$ : represents the total number of subjects in each group with at least one positive reaction. Local 1 and Local 2 indicate the two most frequent allergens specific to the geographical region. ${ }^{*}: \mathrm{p}<0.05$. 
positive skin-prick tests, age and sex, serum total IgE was not associated with asthma severity.

\section{Medications}

Consistent with the inclusion criteria, the median dose of ICS was $666 \mu \mathrm{g}$ for the subjects with controlled asthma and $1,773 \mu \mathrm{g}$ for the severe asthmatics (table 2). The subjects with severe asthma also used other regular treatments to a much greater extent than the subjects with controlled asthma, 95.5\% versus $24.7 \%$ for inhaled long-acting $\beta$-agonists and $45.5 \%$ versus $2.5 \%$ for oral theophylline. A small proportion $(<20 \%)$ of the patients in both groups used additional supplementary treatments (ipatropium bromide, sodium cromoglycate or frequent nebulisation of short-acting $\beta$-agonists), with a nonsignificant trend for greater use among the severe asthmatics. Among the patients with severe asthma there was, in addition, a large subgroup $(n=53)$ that also required regular treatment with OCS (median dose of prednisone $19 \mathrm{mg}$; range $4-50 \mathrm{mg})$.

\section{Medical history}

The duration of diagnosed asthma was the same in the two groups $(20.2 \pm 2.3$ for the controlled versus $20.8 \pm 2.5$ in the severe asthmatics). In a multiple linear regression analysis, the following characteristics showed independent positive association with severe asthma (OR, 95\% CI): female sex (2.69, $1.62-4.49)$, perennial symptoms $(2.9,1.8-4.5)$ and exacerbations during the autumn $(2.42,1.19-4.94)$. Negative associations were found for mother's history of atopy $(0.46,0.27-0.79)$ and a history of allergic rhinitis $(0.59,0.38-0.91)$.

Self-reported trigger factors for worsening of asthma were sex-specific. Amongst the females in the study, independent associations with the asthma severity were found for sinusitis (3.92, 1.88-8.16), premenstrual period $(3.3,1.2-8.13)$, aspirin intake $(5.12,2.14-12.24)$, exercise $(2.36,1.07-2.59)$ and work environment $(2.02,1.5-8.31)$. Amongst the male contingent, relevant triggers were physical exercise $(5.57,1.61-28.3)$, stress $(3.53,1.28-9.71)$ and aspirin intake $(4.61,0.9-21.84)$, but not allergen exposure $(0.30,0.1-0.92)$.

\section{Pulmonary function}

Patients with severe asthma had lower baseline FEV1, lower FEV1/FVC, a significantly reduced VC, increased RV and a trend towards increased RV/TLC ratio (table 4). They also had a marginally reduced $\mathrm{KCO}$, and were slightly hypoxic and hypocapnic at rest (table 4).

\section{Inflammatory markers}

Those with severe disease had a significantly greater number of neutrophils in their sputum, but there was no difference in the number, or proportion, of eosinophils or other leukocytes (fig. 2). Persistent inflammation in those with severe asthma was also reflected in the increased levels of urinary $\mathrm{LTE}_{4}$ and EPX (table 5). While there was no significant differences in exhaled NO levels between the two groups of asthma patients that were evaluated from this marker (table 5), those belonging to the OCS treated group of subjects with severe asthma had levels that were almost threefold higher than those treated only with ICS (median and range, $16.6,10.7-22.5, \mathrm{n}=22$ and $6.4,4.3-9.4, \mathrm{n}=28$, respectively,
Table 4.-Pulmonary function tests (per cent of predicted) and blood gases

\begin{tabular}{|c|c|c|c|}
\hline & $\begin{array}{l}\text { Controlled } \\
\text { asthma }\end{array}$ & $\begin{array}{l}\text { Severe } \\
\text { asthma }\end{array}$ & $\begin{array}{l}\text { Controlled } \\
\text { versus severe } \\
\text { asthma }\end{array}$ \\
\hline Subjects $\mathrm{n}$ & 130 & $133-153^{\#}$ & \\
\hline FEV1 & $88.5 \pm 18.1$ & $71.8 \pm 23.1$ & $\mathrm{p}<0.001$ \\
\hline $\begin{array}{l}\text { FEV1 post } \\
\text { salbutamol }\end{array}$ & $97.6 \pm 17.8$ & $80.9 \pm 24.1$ & $\mathrm{p}<0.001$ \\
\hline FVC & $103.1 \pm 16.1$ & $94.1 \pm 21.1$ & $\mathrm{p}<0.001$ \\
\hline FEV1/FVC & $89.7 \pm 12.8$ & $79.9 \pm 16.6$ & $\mathrm{p}<0.001$ \\
\hline TLC & $104.1 \pm 13.4$ & $104.4 \pm 15.2$ & NS \\
\hline RV/TLC & $104.2 \pm 23.0$ & $113.4 \pm 28.0$ & $\mathrm{p}<0.01$ \\
\hline $\mathrm{KCO}$ & $95.0 \pm 16.7$ & $90.6 \pm 19.0$ & $\mathrm{p}<0.05$ \\
\hline$P \mathrm{a}, \mathrm{O}_{2} \mathrm{kPa}$ & $12.0 \pm 1.6$ & $11.2 \pm 1.9$ & $\mathrm{p}<0.001$ \\
\hline $\mathrm{Pa}, \mathrm{CO}_{2} \mathrm{kPa}$ & $5.1 \pm 0.5$ & $4.9 \pm 0.5$ & $\mathrm{p}<0.01$ \\
\hline $\mathrm{pH}$ & $7.41 \pm 0.03$ & $7.42 \pm 0.03$ & NS \\
\hline $\mathrm{HCO}_{3} \mathrm{mmol} \cdot \mathrm{L}^{-1}$ & $24.8 \pm 2.4$ & $24.3 \pm 2.4$ & NS \\
\hline Base excess $\mathrm{mmol} \cdot \mathrm{L}^{-1}$ & $0.7 \pm 2.3$ & $0.4 \pm 2.2$ & NS \\
\hline
\end{tabular}

Data presented as mean \pm SD. FEV1: forced expiratory volume in one second; FVC: forced vital capacity; TLC: total lung capacity; NS: not significant; RV: residual volume; KCO: carbon monoxide transfer coefficient; $\mathrm{Pa}, \mathrm{O}_{2}:$ arterial oxygen tension; $\mathrm{Pa}, \mathrm{CO}_{2}$ : carbon dioxide arterial tension. \#: Twenty subjects did not perform all spirometry measurements or blood gases.

$\mathrm{p}<0.05)$. Although within the normal range, the severe asthmatics had a higher peripheral WBC dominated by a neutrophilia (table 5). There was no significant difference in the circulating eosinophil count between the two asthma groups.

\section{Discussion}

The ENFUMOSA project has provided the first comprehensive assessment of severe asthma in a variety of centres across Europe. By using strict entry criteria based on principally the presence of an exacerbation in the past year despite treatment with high doses of corticosteroids, each

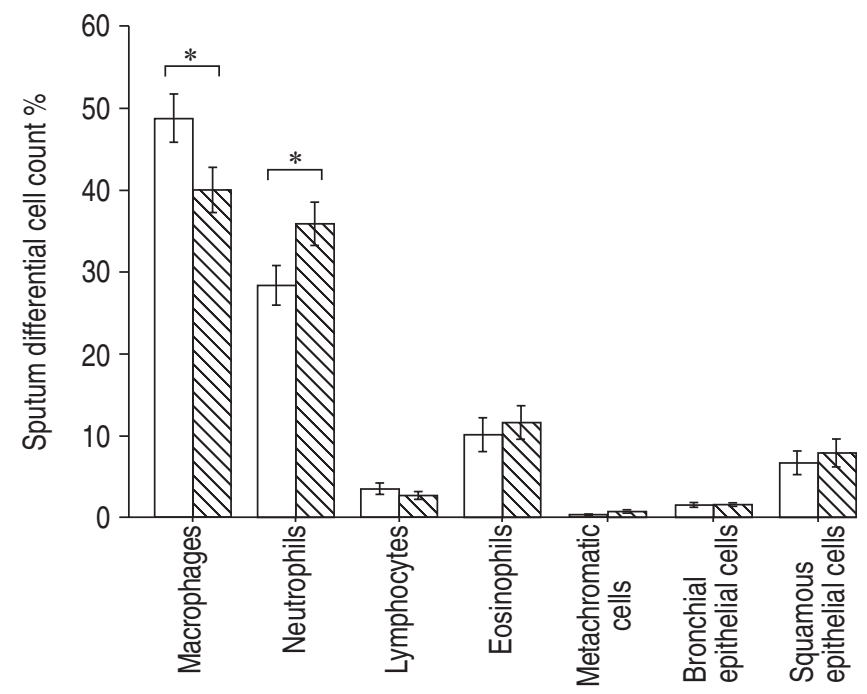

Fig. 2.-Sputum differential cell count in subjects with severe asthma $(\mathbb{\nabla} ; n=99)$ compared with subjects with well-controlled asthma $(\square$; $n=89)$. Data expressed as $\% \pm$ SEM. There were no difference in total sputum cell counts between the groups (controlled asthma $4.6 \pm 0.5$ million cells per gram versus $5.6 \pm 0.6$ million cells per gram in the subjects with severe asthma). ${ }^{*}: \mathrm{p}<0.05$. 
Table 5.-Biomarkers of inflammation

\begin{tabular}{|c|c|c|c|}
\hline & $\begin{array}{l}\text { Controlled } \\
\text { asthma }\end{array}$ & $\begin{array}{l}\text { Severe } \\
\text { asthma }\end{array}$ & $\begin{array}{c}\text { Controlled } \\
\text { versus } \\
\text { severe asthma }\end{array}$ \\
\hline \multicolumn{4}{|l|}{ Peripheral WBC } \\
\hline Subjects $\mathrm{n}$ & 130 & 162 & NS \\
\hline Total count $\times 10^{9} \cdot \mathrm{L}^{-1}$ & $6.7 \pm 1.7$ & $8.6 \pm 3.4$ & $<0.05$ \\
\hline Monocytes \% & $7.2 \pm 2.4$ & $6.5 \pm 2.1$ & NS \\
\hline Neutrophils \% & $57.3 \pm 8.3$ & $61.2 \pm 12.1$ & $<0.05$ \\
\hline Lymphocytes \% & $30.4 \pm 7.1$ & $27.1 \pm 9.3$ & NS \\
\hline Eosinophils \% & $4.1 \pm 3.1$ & $4.4 \pm 5.0$ & NS \\
\hline Basophils \% & $0.7 \pm 0.8$ & $0.7 \pm 0.8$ & NS \\
\hline \multicolumn{4}{|l|}{ Urinary mediators } \\
\hline Subjects $n$ & 136 & 153 & \\
\hline $\begin{array}{l}\mathrm{LTE}_{4} \mathrm{ng} \cdot \mathrm{mmol}^{-1} \\
\text { creatinine }\end{array}$ & $48 \pm 5.8$ & $58 \pm 7.7^{\#}$ & $<0.05$ \\
\hline $\begin{array}{l}\mathrm{EPX} \mu \mathrm{g} \cdot \mathrm{mmol}^{-1} \\
\text { creatinine }\end{array}$ & $45 \pm 4.6$ & $62 \pm 9.3^{\#}$ & $<0.05$ \\
\hline \multicolumn{4}{|l|}{ Exhaled NO } \\
\hline Subjects $n$ & 45 & 50 & \\
\hline $\begin{array}{l}\text { Geometric mean } \\
\operatorname{ppb}^{\#}(95 \% \mathrm{CI})\end{array}$ & $9.2(7.0-7.3)$ & $9.8(7.3-13.2)$ & NS \\
\hline
\end{tabular}

Data are presented as mean \pm SD unless otherwise indicated. WBC: white blood count; $\mathrm{LTE}_{4}$ : leukotriene $\mathrm{E}_{4}$ : EPX: eosinophil protein X; NO: nitric oxide; CI: confidence interval. \#: age and sex adjusted.

clinical centre was able to recruit a sufficient number of patients with severe asthma to enable confident conclusions to be drawn. This allows comparisons with a similarly sized group of subjects with mild-to-moderate well-controlled asthma. Although all patients were recruited through hospital outpatient departments, studied by the same protocol and the diagnosis of asthma was made by specialists, the study was observational and pragmatic in nature and was not an epidemiological survey of representative populations in each country.

The findings reported here may form the basis of new hypotheses concerning the pathophysiology of severe asthma. The data should stimulate further research into severe and chronic airway disease, including population sampling to confirm the phenotypic characteristics observed in this investigation. The selection criteria were carefully chosen to exclude patients with chronic obstructive pulmonary disease (COPD). By recruiting patients from multiple centres in Southern and Northern Europe the project was able to identify common features of severe asthma independently from genetic and geographic environmental factors.

Despite having an almost identical age distribution and duration of disease compared with the controlled disease subjects, those with severe asthma remained symptomatic, even though they were being maintained, for a minimum of $1 \mathrm{yr}$, on significantly higher doses of corticosteroids, inhaled long-acting $\beta_{2}$-adrenoceptor agonist and a range of additional antiasthma drugs. It is theoretically possible that patients enrolled with severe asthma were under-treated or were not taking their medication as prescribed, however, this is unlikely to be a major confounding factor in this particular study. First, the majority of patients were well known for many years to the physicians responsible for their regular care. Second, the willingness to participate in the study, suggests that the majority of patients had severe asthma despite compliance with prescribed treatment. It should be acknowledged that the subjects reported in this paper represent those frequently encountered in the clinical setting, where there is inadequate disease control with currently available therapies. There is clearly a need for more effective therapeutic agents and disease management strategies for this subgroup of asthma.
A striking feature of patients recruited into the ENFUMOSA study is the prominence of females among the subjects with severe asthma. It is theoretically conceivable that there could have been a selection bias, for example the entry criterion of tobacco consumption of $<5$ pack yrs and the availability to attend the clinics during workdays for assessment could have reduced the participation of males with asthma. However, if these were powerful factors influencing patient recruitment, then an equally strong female preference would be expected to have influenced the mild-to-moderate/ well controlled asthma group and the increased ratio of females may mainly have been observed in countries where males dominate the workforce. This however was not the case as the female predominance in the groups with severe asthma was consistent across Europe (table 3). The findings from this project support the hypothesis that severe asthma is a sexrelated disease. The reasons for this remains obscure. The literature on hormonal and sex-related effects on the clinical course of asthma is conflicting. Rather than speculating on the many theoretically possible explanations, it is concluded that the results of this study prompt for further investigations as to why females with asthma experience more severe disease.

The association of severe asthma with an increased body mass index, especially in females, is of particular interest given that similar findings have emerged from a number of studies in children and adults linking asthma with increased weight [14]. It is possible that this represents an effect of sex hormones interacting with glucocorticosteroids on fat and carbohydrate metabolism and electrolyte status. However, this is speculative at present and further research is needed to explore the explanation for this observation.

The increased RV/TLC ratio, hypoxaemia and reduced $K \mathrm{CO}$ in the subjects with severe asthma suggests that there is an important component of fixed and small airway disease in severe asthma. The peripheral airways and/or the alveolar walls may have undergone structural changes as a consequence of ongoing disease even in the presence of high-dose inhaled and oral corticosteroid use. As in COPD this may reflect parenchymal involvement with loss of alveolar attachment to the airways and some destruction of alveolar walls [15]. These findings highlight the need for further investigations, including biopsy studies, in order to evaluate the degree of chronic airway remodelling in severe asthma, and the extent of such changes in the small airways.

Although atopy is considered to be one of the strongest risk factors for developing asthma [7, 16], a number of findings in the ENFUMOSA study suggests that atopy is less important as a predictor of the development of severe asthma. Thus, the group with severe asthma had lower total serum IgE, fewer positive skin-prick tests, radioallergosorbent tests to common allergens and an inverse relationship to a family history of atopy among the severe asthmatics was observed. Likewise, exacerbations were more frequent in the autumn rather than during the pollen season. While in severe asthma the seasonal pattern of worsening symptoms may reflect dust mite sensitisation, skin-prick positivity and specific IgE against house dust mite was significantly less than that observed in the well-controlled asthmatics. Other environmental factors are probably more important, including infections with viruses and possibly other microorganisms and the influence of fungal exposure, specifically Aspergillus fumigatus and Alternaria. There are indications that the persistence of Chlamydia pneumoniae and Mycoplasma pneumoniae and viral infections are linked to worsening of asthma [17-19] and it is hypothesised that infections rather than allergy may have a pathogenetic role for the development of severe asthma.

The eosinophil, with its capacity to release a range of inflammatory mediators, is often seen as the principal inflammatory cell linked to airway dysfunction in asthma. 
However, recent findings [20-21] question the pivotal role that this cell has in asthma pathogenesis. Thus, while the study was unable to find any significant differences in the circulating eosinophil count between the patient groups, the persistence of eosinophils in induced sputum and the presence of increased urinary $\mathrm{LTE}_{4}$ and EPX, despite inhaled and oral corticosteroid treatment, provided the evidence that in severe asthma disease the inflammatory response is inadequately controlled. Persistent airway eosinophilia and T-cell activation in the presence of corticosteroids has been found in other studies of chronic asthma [3, 4, 22] and implies that corticosteroids are not adequately suppressing the inflammatory process. The increased excretion of NO in exhaled air observed in those asthmatics taking regular oral corticosteroids is further evidence of persistent airway inflammation and possible relative resistance to steroid treatment since, in mild-to-moderate disease, inducible NO synthase in the bronchial epithelium is highly sensitive to suppression with corticosteroids [23]. Thus, another hypothesis emerging from the ENFUMOSA study is that severe asthma might be characterised by a diminished or suboptimal sensitivity to glucocorticosteroids.

Another finding in the ENFUMOSA study was the presence of increased neutrophils in the circulation and in the sputum. Until recently, neutrophilia has been regarded more as a feature of COPD than asthma. However, increased airway neutrophils have been shown in virus-induced exacerbations of asthma [24] and in sudden onset fatal asthma [25]. Although corticosteroids are able to produce an acute increase in circulating neutrophils, patients in this study were on long-term therapy and had not received an additional corticosteroid course within 4 weeks of enrolment. Corticosteroids have also been reported to protect neutrophils from apoptosis which may contribute to their potential adverse role in chronic and severe disease [26]. This is important because the neutrophil has the capability of causing tissue destruction as occurs in COPD [15].

A potential risk factor for severe asthma that emerged from the ENFUMOSA study was exposure to aspirin. It has long been recognised that NSAIDs can precipitate asthmatic bronchoconstriction in $10-20 \%$ of adults with asthma, and the occurrence of such aspirin-intolerant asthma (AIA) appears more prevalent among subjects with severe varieties of asthma $[8,27]$. Recent research suggests that AIA with its characteristic complex of rhinosinusitis, nasal polyps and flushing, results from excess formation of cysteinyl leukotrienes in the airways [28]. The study's findings of high LTE $_{4}$ levels in the urine of the patients with severe asthma supports the possibility for the mediator pathway to be operative despite corticosteroid treatment and raises the important possibility that antileukotriene therapy with either a 5-lipoxygenase inhibitor (e.g. zileuton) or a cysteinyl leukotriene-1 ( $\left.\mathrm{LT}_{1}\right)$ receptor antagonist (e.g. zafirlukast, montelukast) would provide added benefit. In addition antileukotriene treatment has been shown to be of some benefit when added to inhaled steroids both in severe asthmatics selected on the basis of aspirin intolerance [29, 30], and in other groups of asthmatics with more severe disease $[31,32]$.

In conclusion, the European Network For Understanding Mechanisms Of Severe Asthma (ENFUMOSA) study has identified features of severe asthma that are distinct from those described for mild-to-moderate disease. Persistent symptoms and abnormal lung function, despite high-dose regular use of controller and reliever medications, is accompanied by a component of irreversible airflow obstruction, neutrophilic inflammation, ongoing mediator release and reduced association with atopy. The authors suggest that severe asthma has features shared with chronic obstructive pulmonary disease. The authors also believe that the identification of factors which predict the development of severe asthma require further investigations so as to test the hypothesis that severe asthma is a different form of the disease with features that are distinct from those classically known for mild-to-moderate asthma.

\footnotetext{
Acknowledgements. The authors are grateful to the many dedicated people in the clinical centres who helped with the conduct of the study, collection of laboratory samples and the patient evaluations, to W. Couper who typed the manuscript, and R. Middelveld who integrated comments and corrections from the ENFUMOSA team.
}

\section{References}

1. Barnes PJ, Woolcock AJ. Difficult asthma. Eur Respir J 1998; 12: 1209-1218.

2. Serra-Batlles J, Plaza V, Morejou E, Cornella A, Brugues J. Costs of asthma according to the degree of severity. Eur Respir J 1998; 12: 1322-1326.

3. Wenzel SE, Schwartz LB, Langmack EL, et al. Evidence that severe asthma can be divided pathologically into two inflammatory subtypes with distinct physiologic and clinical characteristics. Am J Respir Crit Care Med 1999; 160: 10011008 .

4. Louis R, Lau LCK, Bron AO, Roldaan AC, Radermecker M, Djukanovic R. The relationship between airways inflammation and asthma severity. Am J Respir Crit Care Med 2000; 161: 9-16.

5. in't Veen JCCM, Smits HH, Hiemstra PS, Zwinderman AE, Sterk PJ, Bel EH. Lung function and sputum characteristics of patients with severe asthma during an induced exacerbation by double-blind steroid withdrawal. Am J Respir Crit Care Med 1999; 160: 93-99.

6. Lange P, Parner J, Vesbo J, Schohr P, Jensen G. A 15 year follow-up of ventilatory function in adults with asthma. $N$ Eng J Med 1998; 339: 1194-1200.

7. Murray CS, Woodcock A, Custovic A. The role of indoor allergen exposure in the development of sensitization and asthma. Curr Opin Allergy Clin Immunol 2001; 1: 407412 .

8. Szczeklik A, Stevenson DD. Aspirin-induced asthma: advances in pathogenesis and management. $J$ Allergy Clin Immunol 1999; 104: 5-13.

9. Redier H, Daures J-P, Michel C, et al. Assessment of the severity of asthma by an expert system: description and evaluation. Am J Respir Crit Care Med 1995; 151: 345352.

10. Quanjer PH, Tammeling GJ, Cotes JE, Pedersen OF, Peslin R, Yernault JC. Lung volumes and forced ventilatory flows. Report working party standardisation of lung function tests. European Community for Steel and Coal. Eur Respir J 1993; 6: Suppl. 16, 5-40.

11. Cotes JE, Chinn DJ, Quanjer PH, Roca J, Yernault J-C. Standardisation of the measurement of transfer factor (diffusing capacity). Eur Respir J 1993; 6: Suppl. 16, 4152.

12. Pizzichini E, Pizzichini MMM, Efthimiades A, et al. Indices of airway inflammation in induced sputum: reproducibility and validity of cell and fluid-phase measurements. $\mathrm{Am}$ J Respir Crit Care Med 1996; 154: 308-317.

13. Kumlin M, Stensvad F, Larsson L, Dahlén B, Dahlén S-E. Validation and application of a new simple strategy for measurements of leukotriene $\mathrm{E}_{4}$ in human urine. Clin Exp Allergy 1995; 25: 467-479.

14. Shaheen SO. Obesity and asthma: cause for concern. Clin Exp Allergy 1999; 29: 291-293. 
15. O'Byrne PM, Postma DS. The many faces of airway inflammation - asthma and chronic obstructive pulmonary disease. Am J Respir Crit Care Med 1999; 159: S41-S66.

16. Kauffman F, Dizier M-H, Pin I, Paty E, et al. Epidemiological study of the genetics and environment of asthma, bronchial hyperresponsiveness and atopy. Am J Respir Crit Care Med 1997; 156: S123-129.

17. Cunningham AF, Johnston SL, Julious SA, Lampe FC, Ward ME. Chronic Chlamydia pneumoniae infection and asthma exacerbations in children. Eur Respir J 1998; 11: 345349.

18. ten Brinke A, van Dissel JT, Sterk PJ, Swinderman AH, Rabe KF, Bel E. Persistent airflow limitation in adult-onset non-atopic asthma is associated with serologic evidence of Chlamydia pneumoniae infection. J Allergy Clin Immunol 2001; 107: 449-454.

19. Kraft M, Cassell GH, Hensen JE, et al. Detection of Mycoplasma Pneumoniae in the airways of adults with chronic asthma. Am J Respir Crit Care Med 1998; 158: 998-1001.

20. Leckie MJ, Ten Brinke A, Khan J, et al. Effects of an interleukin-5 blocking monoclonal antibody on eosinophiles, airway hyperresponsiveness and the response to allergen in patients with asthma. Lancet 2000; 356: 2144-2148.

21. Bryan SA, O'Connor BJ, Matti $\mathrm{S}$, et al. Effects of recombinant human interleukin-12 on eosinophiles, airway hyper-responsiveness, and the late asthmatic response. Lancet 2000; 356: 2149-2153.

22. Wenzel SE, Szefler SJ, Leung DYM, Sloan SI, Rex MD, Martin RJ. Bronchoscopic evaluation of severe asthma. Am J Respir Crit Care Med 1997; 156: 737-743.

23. Trifilieff A. Role of the inducible form of nitric oxide synthase in lung inflammation. Eur Respir Rev 2000; 10: 73, 246-248.

24. Pizzichini MM, Pizzichini E, Efthimiadis A, et al. Asthma and natural colds. Inflammatory indices in induced sputum: a feasibility study. Am J Respir Crit Care Med 1998; 158: $1178-1184$.

25. Sur S, Crotty TB, Kephart GM, et al. Sudden-onset fatal asthma. A distinct entity with few eosinophiles and relatively more neutrophils in the airway submucosa. Am Rev Respir Dis 1993; 148: 713-719.

26. Strickland I, Kisich K, Hauk PJ, et al. High constitutive glucocorticoid receptor $\beta$ in human neutrophils enables them to reduce their spontaneous rate of cell death in response to corticosteroids. J Exp Med 2001; 193: 585-594.

27. Szczeklik A, Nizankowska E, Duplaga M, on behalf of the AIANE investigators. Natural history of aspirin-induced asthma. Eur Respir $J$ 2000; 16: 432-436.

28. Cowburn AS, Sladek K, Soja J, et al. Overexpression of leukotriene $\mathrm{C}_{4}$ synthase in bronchial biopsies from patients with aspirin-intolerant asthma. J Clin Invest. 1998; 101: 834846.

29. Dahlén B, Nizankowska E, Szczeklik A, et al. Benefits from adding the 5-lipoxygenase inhibitor zileuton to conventional therapy in aspirin intolerant asthmatics. Am J Respir Crit Care Med 1998; 157: 1187-1194.

30. Dahlén S-E, Malmström K, Nizankowska E, et al. Improvement of aspirin-intolerant asthma by montelukast, a leukotriene antagonist. A randomised, double-blind, placebo controlled trial. Am J Respir Crit Care Med 2002; 165: 914.

31. Tamaoki J, Kondo M, Sakai N, et al. Leukotriene antagonist prevents exacerbation of asthma during reduction of highdose inhaled corticosteroid. Am J Respir Crit Care Med 1997; 155: 1235-1240.

32. Virchow C, Prasse A, Naya I, Summerton L, Harris A. Zafirlukast improves asthma control in patients receiving high-dose inhaled corticosteroids. Am J Respir Crit Care Med 2002; 162: 578-585. 